\title{
Spatial Distribution of Trophic Groups of Amoebae Around the Root Zone of Zea Mays Mycorrhizal With Rhizophagus Intraradices Grown in Microcosms
}

\author{
Sandra Cortes-Pérez \\ Colegio de Postgraduados \\ Ronald Ferrera-Cerrato ( $\square$ rferreracerrato@gmail.com ) \\ Colegio de Postgraduados \\ Salvador Rodríguez-Zaragoza \\ Universidad Nacional Autonoma de Mexico \\ Alejandro Alarcón \\ Colegio de Postgraduados
}

\section{Research Article}

Keywords: mycorrhizal interactions, mycorrhizosphere, hyphosphere, soil amoebae, trophic groups, amoebae distribution in soil

Posted Date: December 8th, 2021

DOl: https://doi.org/10.21203/rs.3.rs-1105474/v1

License: (-) This work is licensed under a Creative Commons Attribution 4.0 International License. Read Full License 


\section{Abstract}

Fitness and productivity of most terrestrial plants depend on early associations with arbuscular mycorrhizal fungi and mutualistic bacteria. Plants select most of the microbial communities cohabiting their roots and mycorrhizosphere, attracting also all types of microbial predators. Naked amoebae are among the most voracious predators inflicting significant changes in soils bacterial and fungal populations. We evaluated how roots of Zea mays with or without Rhizophagus intraradices mycorrhizosphere (AMF) influence trophic groups of amoebae, along vertical (3, 6, and 9-cm) and horizontal soil distribution (roots and free-root compartments) grown in microcosms after, 20 days. Amoebae community in Non-AMF showed a high species richness in the root zone at 3 to $6-\mathrm{cm}$ depth, and at the two free-root compartment away from plants. Conversely, AMF and mycelium zones modified the amoeba community at 6 to $9-\mathrm{cm}$ depth, recording higher diversity of trophic groups than unplanted soil compartments. The highest bacterivorous diversity was found at the closer compartment to AMF roots, but fungivorous amoebae was not recorded. Amoebae feeding preferences were similar in both AMF and Non-AMF microcosms in where bacterivorous amoebae were dominant, while protozoa-eating amoebae were more frequent at the mycelium compartments. Rare amoebae species were found in AMF microcosms in comparison to those recorded from Non-AMF and unplanted microcosms.

\section{Introduction}

Productivity ecosystem and agrosystems [1] are based on interactions among plants-bacteria-fungi. Arbuscular mycorrhizal fungi (AMF) are determinant for soil nutrient mobilization, and plant nutrient uptake and productivity [2-4]. Once AMF are successfully established, metabolic activity and extraradical-mycelium exudation create specific microenvironments that modify the microbial community composition and their physiological activities (mycorrhizosphere effect [5, 6]). This functional zone has two main components: 1) rhizosphere with AMF-mycelium, and 2) hyphosphere integrated by AMF-hyphae network [7].

Fungal exudates from mycorrhizosphere generate hotspots for microbial communities with higher functional diversity [8-10]. Similarly, AMFhyphosphere increases plant nutrient uptake from distant soil matrixes and also allows specific bacterial activities around hyphae [7, 8, 10] and spores [11], that enhance spore germination, hyphal growth, and root colonization [12,13]. Hyphal exudates of some AMF species increase the abundance of Oxalobacteraceae, Streptomycetes and Firmicutes [14, 9, 10], around and inside AMF mycelium [10]. Furthermore, hyphae-associated bacteria may provide protection against fungal grazers, promote root colonization $[15,16]$. Conversely Acidobacteria, Bacteriodetes, Firmicutes and Proteobacteria species can suppress mycorrhizal development [17] as well as microorganisms that cause plant diseases [18-21].

Plant and fungal exudations attract predators which enhance nutrient cycling around root systems and mycorrhizosphere [22]. Protozoa locate their preys through recognition of chemical signals produced by plants and microorganisms [23]. Thus, prey selection and consumption are based on bacterial exudates, sizes, and palatability [23-25].

Amoeba are main bacterial predators from soil [22, 23, 26-28], and almost every amoebae species temporarily survive by feeding on bacteria. However, amoebae feed on different kind of organisms, and based on their feeding preferences, can be grouped as bacterivorous, fungivorous, yeasteaters, algae-eaters, protist-eaters, and omnivorous. This interactions predator-preys are part of Microbial Loop phenomenon that boistimulate the plant growth. [29]. Amoebae community develops within a short distance of plant-microbial hotspots. However, how trophic groups of amoebae influence productivity and trophic web is still unknown in general. Thus, we addressed the question about how AMF (Rhizophagus intraradices) colonizing roots of Zea mays may modify the structure of amoebae trophic groups along vertical distribution (3, 6, and 9-cm depths) after 20 days? Then, we aimed to determine the short-term effects of AMF and roots of Z. mays on amoebae community in a microcosms study.

\section{Material And Methods Soil volume determination}

Twenty-four composite sandy-soil samples were taken from roots zone of non-mycorrhizal pots planted with Zea mays at V8 stage. Each sample (1 g dry weight), was homogenized in $10 \mathrm{~mL}$ of sterile sandy-soil-extract solution (1:10 v/v) by shaking twice at $2000 \mathrm{rpm}$ during $30 \mathrm{~s}$. After allowing soilparticles sedimentation (30 min), supernatant was poured on soil-extract agar. Then Petri dish tilted at 10 degrees for $2 \mathrm{~h}$ to facilitate trophozoites attaching on agar surface. Excess water was removed with sterile Pasteur pipette carried out into sterile conditions [30]. Petri dishes were incubated at $28^{\circ} \mathrm{C}$ and reviewed daily for 3 weeks for amoebae identification (Table S1).

\section{Amoebae Observation}

Fresh preparations were used to visualize amoebae. Trophozoites were recuperated by suspension through scraping on agar with loopful in $300 \mathrm{~L}$ sterile distillated water. This suspension was recovered with a sterile Pasteur pipette and poured on slide and spread with coverslip. Preparations were allowed to settle down in humid chamber during $3 \mathrm{~h}$ before observation with BX51 phase contrast microscope at 20X, 40X and 100X magnifications. Amoebae videos were recorded for id corroboration (40X). Morphological identification was based on specialized keys [1-6] as well as specialized papers. 


\section{Soil-extract (Stock Solution)}

Sandy-soil suspensions ( $300 \mathrm{~g} / 1 \mathrm{~L}$ distillated water) were placed in water bath at $60^{\circ} \mathrm{C}$ for $3 \mathrm{~h}$ and filtered throughout Wathman No.2 filter paper; filtrate was sterilized and stored at $4^{\circ} \mathrm{C}$ until utilization. Solid medium was prepared by dissolving bacteriological-agar $15 \mathrm{~g} / \mathrm{L}$ in soil-extract working solution (diluting 1:5 v/v, soil-extract/water). Soil-extract solution used to homogenize soil subsamples was prepared at 1:10 v/v [30].

\section{Microcosms and experimental settings}

Microcosms (6 unities) were fabricated as rectangular acrylic containers of $18 \mathrm{~cm}$ length $\times 12 \mathrm{~cm}$ wide $\times 10 \mathrm{~cm}$ height. Microcosms were divided in three compartments filled up with $350 \mathrm{~g}$ of sterilized sand and separated by two stainless-steel meshes, pore size: $44 \mu \mathrm{m}$, this pores allows AMFhyphae passing to adjacent compartments while restricting roots passing (Fig S1).

\section{Microbial inoculum (slurry)}

Ninety grams of sandy soil from non-mycorrhizal roots of Zea mays (V8 stage) were homogenized by shaking (5-pulses for 1 min at 2000 rpm) in 810 $\mathrm{mL}$ sterile soil-extract (1:10 v/v). Solution was vacuum filtered, with a Kitasato flask and Buchner funnel with Whatman paper Grade-4 (20-25 $\mu \mathrm{m})$ to allow protists and bacteria passage. Slurry was shaken with a magnetic stirrer at low velocity to keep microorganisms suspended until inoculation [30].

\section{Microcosms inoculation}

Microorganisms were inoculated by adding $50 \mathrm{~mL}$ of slurry in each compartment from all microcosms, which were placed in growth chamber [ $12 \mathrm{~h}$ photoperiod; $400 \mathrm{~W} \mathrm{Na-vapor} \mathrm{lamps,} 24^{\circ} \mathrm{C}$ (maximum) and $12^{\circ} \mathrm{C}$ (minimum)] for 20 days. Microcosms were kept at $60 \%$ water-holding capacity by watering every two days with sterilized tap water (Fig S2).

\section{Experimental treatments}

Inoculated microcosms were divided in to set three treatments by duplicate: a) unplanted-microcosms (Control=C); b) non-inoculated 8-days old Zea mays seedlings (N/AMF) transplanted at compartment $1(\mathrm{Cl})$, and c) Z. mays seedlings inoculated with $R$. intrarradices (AMF) [46]. Plant inoculation was performed with 150 AMF-spores $/ \mathrm{mL}^{-1}$ (10 g-inoculum). Mycorrhizal-inoculum was provided by Corporativo de Desarrollo Sustentable S.A. de C.V., Morelia, Michoacan (Mexico). Compartments 2 and 3 (CII and CIII) were also inoculated with AMF-inoculum.

Previously, seeds were disinfested by washing them with $10 \% \mathrm{NaClO}$ for 5 min, rinsed and germinated in Petri dishes with autoclaved sand ( $121^{\circ} \mathrm{C}$ for $3 \mathrm{~h}$ ) kept at room temperature for 8 days. All microcosms were kept growth chamber conditions and kept soil at $60 \%$ of water-holding capacity for 20 days (Fig S2).

\section{Sampling-soil from microcosms}

Sampling-soil was achieved with PVC tubes (corer) with 10-cm long and 1.5-cm diameter; by quadruplicate for every compartment taking carefully a square of 3-cm between sampling-corer points. Corer was sown to 9 -cm depth, provided $9 \mathrm{~g}$ of sand-sample allowing to obtain $3 \mathrm{~g}$ of sandy-soil from 3, 6 and 9-cm depths. Each $3 \mathrm{~g}$ sample was processes independently, obtaining $108 \mathrm{~g}$ of sandy-soil in 34 samples from each microcosms (Fig S2).

\section{Amoebae trophic preferences}

Amoebae feeding preferences were grouped into 6 categories: bacterivorous $(B)$, fungivorous $(F)$, algal-eaters $(A)$, protozoa-eaters $(P)$, omnivorous $(0)$, and non-determined trophic group (ND) following the reports provided in the literature (Tables S1, S4).

\section{Morphotypes and Most Probable Number (MPN) of amoebae, and mycorrhizal parameters}

MPN of amoebae morphotypes from every subsample was determined with $1 \mathrm{~g}$ sandy soil homogenized in sterile soil-extract (10 $\mathrm{mL}$ : 1:10 $\mathrm{v} / \mathrm{v}$ ). Sequential serial dilutions from $10^{-1}$ to $10^{-6}$, were dispensed in 24 -well microplates. Aliquot of $100 \mu \mathrm{L}$ from each dilution was dispensed in their corresponding row by quadruplicate (Fig S3). Morphotypes (I-XII, Fig. 1) were registered in every microplate after inverted microscope examination. MPN calculation was performed with Thomas formula [30]. 
MPN $=\frac{\text { Number of positive tubes }}{\sqrt{(\text { Number of mL of sample of negative tubes }) x(\text { Number of mL of all tubes })}} \times 100$

Determination of AMF colonization in roots of Zea mays was done in accordance too Phillips and Hayman procedure [31], and total length of AMF mycelium was performed by Tennant method [32].

\section{Statically Analysis}

Amoebae species richness were utilized for estimating gamma diversity: 1) number of species observed, 2) second-order jackknife estimate, 3) Chao2 estimate, classic form, 4) Chao2 estimate bias corrected form (Table S2). Rarefaction analysis indicated $15 \mathrm{~g}$ as minimum volume to make comparison between communities from treatments and slurry preparation, with $70 \%$ of amoebae species recognized in soil composite sample from V8 maize-microcosms (Table S1, Fig S4). Sørensen similitude index was calculated by PC Ord@ software ver. 7 for Windows $\odot$ (dendrograms were calculated by centroid and Bray-Curtis technique) [33]. Trophic diversity was calculated by Shannon index: $\mathrm{H}^{\prime} ; \mathrm{H}^{\prime}=\mathrm{eH} \mathrm{H}^{\prime}=\mathrm{e}-\llbracket \mathrm{p} i \mathrm{Ln} \mathrm{P} ;$; where $\mathrm{P} i$ is the proportion of $i$-th species inside a trophic group [34]. Simpson diversity index was calculated by equation: $D=1 / \mathbb{\nabla}(n i / N)^{2}$ where $n i$ is species richness in each trophic group $i$, and $\mathrm{N}$ is species number total [35]. Data obtained were compared by Chi-squared test [36]. $\beta$ diversity was calculated by three algorithms: 1) Whittaker measures (1972) $\beta_{w}=s / \bar{\alpha}-1$, where $s$ species number recorded is total in each system, and $\bar{\alpha}$ is average species number found within community samples. 2) Cody (1975) or biotic change measure inside gradient habitat, $\beta c=g(H)+I(H) / 2$, where $g(H)$ were species gained and $\mathrm{I}(\mathrm{H})$ were species losses. 3) Cody (1993) $\beta c o=1-\mathrm{C}\left(\mathrm{T}_{1}+\mathrm{T}_{2}\right) / 2 \mathrm{TT}_{2}$, where $\mathrm{T}=\Sigma e_{i}=\Sigma a_{j} ; \mathrm{C}=$ species in common between two censuses; $\mathrm{T} i=$ total number of species in census $i 4) \beta_{T}$ ("beta turnover", Wilson and Shmida, 1984), combines species turnover by gaining ( $g$ ) and losing ( () species along gradient, $\beta_{T=} g(\mathrm{H})+/(\mathrm{H}) / 2 \bar{\alpha}$ [37]. Pearson's correlation ( $\left.\rho\right)$ was calculated between 1) MPN with mycelium length, and 2$)$ amoebae species richness with mycelium length (Excel program Windows@).

\section{Results}

\section{Amoebae MPN}

Control showed in total, 3,243 individuals per $\mathrm{g}^{-1}$ soil-dry-weight (i $\mathrm{g}^{-1} \mathrm{sdw}$ ), and $\mathrm{Cl}$ showed $1023 \mathrm{i} \mathrm{g}^{-1}$ sdw at 9-cm depth (Table 1 ). Morphotypes $\mathrm{VI}$ (Amoebidae: $225 \mathrm{i} \mathrm{g}^{-1} \mathrm{sdw}$ ) and VII (Leptomyxidae: $151 \mathrm{i} \mathrm{g}^{-1} \mathrm{sdw}$ ) were dominant at 9-cm depth from Cl. Morphotype II (Platyamoeba: $151 \mathrm{i} \mathrm{g}^{-1} \mathrm{sdw}$ ) was dominant at 9-cm depth in CII. Morphotypes VII (191 i g $\left.{ }^{-1} \mathrm{sdw}\right)$ and III (Hartmannella: $112 \mathrm{i} \mathrm{g}^{-1}$ sdw) were dominant for CIII (Fig. 2a; $\mathrm{x}^{2}$, P = 0.05; Table S3).

Table 1

Species richness (SR) and most probable number (MPN) of soil free-living amoebae in Unplanted (control) sandy soil (A), N/AMF planted sandy soil (B), and AMF-planted sandy soil (C). Columns (C-I, C-II and C-III) corresponding to compartments of the mycorrhizospheric-box. The species richness is the account of different species recorded in the three compartments rather than the sum of each compartment. The total number of species richness by layer (SRT) and the total MPN by layer I are also included. Row headings: 3-cm, 6-cm and 9-cm are the sampling depths. Row heading: Total by MPN is the sum of quantities reported in the 3 depths $(3,6$ and $9-\mathrm{cm})$

\begin{tabular}{|c|c|c|c|c|c|c|c|c|c|c|c|c|c|c|c|c|c|c|}
\hline & \multicolumn{6}{|c|}{ Control } & \multicolumn{6}{|c|}{ N/AMF } & \multicolumn{6}{|c|}{ AMF } \\
\hline & $\mathrm{Cl}$ & & CII & & CIII & & $\mathrm{Cl}$ & & Cll & & CIII & & $\mathrm{Cl}$ & & Cll & & CIII & \\
\hline & SR & MPN & SR & MPN & SR & MPN & SR & MPN & SR & MPN & SR & MPN & SR & MPN & SR & MPN & SR & MPN \\
\hline $3 \mathrm{~cm}$ & 12 & 266 & 12 & 222 & 10 & 662 & 31 & 703 & 22 & 476 & 10 & 618 & 31 & 870 & 41 & 549 & 16 & 288 \\
\hline $6 \mathrm{~cm}$ & 15 & 188 & 16 & 330 & 10 & 132 & 44 & 303 & 26 & 139 & 14 & 351 & 32 & 500 & 48 & 691 & 17 & 474 \\
\hline $9 \mathrm{~cm}$ & 19 & 569 & 9 & 349 & 12 & 524 & 25 & 674 & 23 & 472 & 19 & 214 & 41 & 69 & 54 & 427 & 29 & 605 \\
\hline $\begin{array}{l}\text { SR by } \\
\text { compartment }\end{array}$ & 26 & & 20 & & 18 & & 60 & & 33 & & 23 & & 47 & & 57 & & 29 & \\
\hline SRT & 27 & & & & & & 65 & & & & & & 73 & & & & & \\
\hline $\begin{array}{l}\text { Total by } \\
\text { column MPN }\end{array}$ & & 1023 & & 902 & & 1318 & & 1679 & & 1087 & & 1183 & & 1439 & & 1667 & & 1368 \\
\hline
\end{tabular}

N/AMF presented in total, 3,950 $\mathrm{i} \mathrm{g}^{-1} \mathrm{sdw}$ (Table 1). Root-zone showed a MPN =1,679 $\mathrm{i} \mathrm{g}^{-1} \mathrm{sdw}$. Cl showed $703 \mathrm{i} \mathrm{g}^{-1} \mathrm{sdw}$ at 3-cm depth (Table 1). Morphotype VIII exhibited $603 \mathrm{i} \mathrm{g}^{-1} \mathrm{sdw}$ at 9-cm depth for Cl. Morphotype VIII dominated at 3-cm and 9-cm depth from CII. Morphotype IV (Saccamoeba: $329 \mathrm{i} \mathrm{g}^{-1} \mathrm{sdw}$ ) at 3-cm from Cl. Morphotypes II and III showed 191 and $226 \mathrm{i} \mathrm{g}^{-1}$ sdw, respectively, from CIII at 3-cm depth (Fig. 2b; $\mathrm{x}^{2}$, P = 0.05; Table S3). 
AMF treatment showed 4,473 $\mathrm{i} \mathrm{g}^{-1} \mathrm{sdw}$ (Table 1). Although root-zone displayed 1,439 $\mathrm{i} \mathrm{g}^{-1} \mathrm{sdw}$, and Cll showed 1,667 i g ${ }^{-1} \mathrm{sdw}$, in total. Cl showed $870 \mathrm{i} \mathrm{g}^{-1} \mathrm{sdw}$ at 3-cm, in which morphotypes III, VI, X (Tetramitus) and VIII registered 224, 149, 118 and $114 \mathrm{i} \mathrm{g}^{-1} \mathrm{sdw}^{-1}$ 3-cm depth Morphotype X was dominant at all depths (112 to $217 \mathrm{i} \mathrm{g}^{-1} \mathrm{sdw}$ ) from Cll, and morphotype V (Mayorella) exhibited $191 \mathrm{i} \mathrm{g}^{-1}$ sdw at CIII (Fig. 2C; $\mathrm{x}^{2}$, P = 0.05; Table S3).

\section{Distribution And Species Richness}

Control treatment registered 27 species (21 genera from 9 families; Table S4). Species richness along depths stayed constant, except for Cl (Table 1). One species was exclusive in this treatment.

N/AMF treatment recorded 65 species at 30 genera from 19 families (Table S4). Cl presented 44 species at 6-cm depth while CII 26 species were recorded at same depth. In contrast, CIII showed the fewest species richness (Table 1). Seventeen species were registered exclusively in this treatment.

For AMF treatment, 73 species were registered, which consisted in 34 genera from 18 families (Table S4). Cl showed 41 species at 9-cm depth. CII registered 54 species at 9 -cm depth $\left(x^{2} \mathrm{P}=0.05\right.$; Table 1). This treatment showed 20 species as exclusive.

\section{Proportion And Diversity Trophic Groups}

Regardless sampled depth and compartment, the most abundant trophic group was bacterivorous (B) amoebae (>60\%) at all treatments (Fig. 3a,b,c). the fungivorous (F) trophic group only was found at 3-cm depth from AMF treatment, when compared to Control and N/AMF treatments in which the proportion of this trophic group was about $20 \%$ (Fig. 3b). In general, protozoa-eater amoebae (P) was registered in all treatments and compartments, excepting at CIII from AMF treatment at any sampled depth (Fig. 3c).

For control treatment, trophic diversity showed highest values for $\mathrm{H}^{\prime}$ and $\mathrm{D}^{\prime}$ indexes (1.2 and 0.9, respectively) at $\mathrm{Cl}$ and $\mathrm{CIII}$ (Table S5), but the highest value of $\mathrm{H}^{\prime}=1.4$ was recorded from $\mathrm{Clll}$ at 9-cm depth (Fig. 3d, Table S6). In contrast, N/AMF treatment showed highest $\mathrm{H}^{\prime}$ and $\mathrm{D}^{\prime}$ indexes (1.3 and 0.75 , respectively) at $\mathrm{Cl}$ and $\mathrm{CIII}$, which were similar to those indexes estimated for $\mathrm{AMF}$ treatment $\left(\mathrm{H}^{\prime}=1.4\right.$ and $\left.\mathrm{D}^{\prime}=0.6\right)$ at $\mathrm{Cl}(\mathrm{Table} \mathrm{S} 5)$. Regarding sampled depth, N/AMF showed values of $\mathrm{H}^{\prime}=1.4$ at $6-\mathrm{cm}$ depth, and $\mathrm{D}^{\prime}=0.7$ at 3-cm depth, both from $\mathrm{Cl}$. For AMF treatment the highest value of $\mathrm{H}^{\prime}$ (1.2) was achieved at 3 and 9-cm depth from $\mathrm{Cl}$, whereas for 6 and 9-cm the $\mathrm{H}^{\prime}$ value was similar (1.2) at Cll (Fig. 3d; Table S6).

\section{Beta diversity}

Species compositional change (Whittaker descriptor) among compartments from N/AMF treatment was $\beta_{w}=2$; whereas for treatments Control and AMF the $\beta_{w}$ values among compartments, ranged between 1.2 and 1.4, respectively. In N/AMF treatment, $\beta$ w was of 1.2 among 3 and 6 -cm depth from CIII; but for $\mathrm{Cl}$ the $\beta$ w was of 1.3 at between 6 and 9-cm depth (Fig. 4). For AMF treatment, $\beta_{w}$ value was of 1.3 between 3 and 6 -cm depth, for CIII (Fig. $4 a)$. Overall, the $\beta_{w}$ values for the control treatment were as follows: $\mathrm{ClII}>\mathrm{Cll}>\mathrm{Cl}$; for N/AMF treatment values were $\mathrm{ClII}>\mathrm{Cl}>\mathrm{Cll}$; and for $\mathrm{AMF}$ treatment the $B_{w}$ values were $\mathrm{CIII}>\mathrm{Cl}>\mathrm{Cll}$ (Fig. 4a; Table S7). Regardless sampled depth and microcosm compartments, $B_{w}$ values for the treatment effect were as follows: N/AMF (2.0) > AMF (1.8) = Control (1.8) (data not shown).

\section{Beta diversity with specific gradient (sampled depth)}

Cody index $\left(\beta_{C}\right)$ from Control treatment ranged from 7 to 5 among the three sampled depths from the three compartments (Fig. $4 \mathrm{~b}$ ). The $\beta_{C}$ value of $\mathrm{Cl}$ from treatment N/AMF was of 16, but at their adjacent compartments (CII and CIII) showed lower values (Fig. 4b). In AMF treatment, $\beta_{C}$ values ranged from 8 to 11, and the highest value was recorded at Cll among 6 and 9-cm depth (Fig. 4b; Table S7).

Control treatment showed a beta turnover index ( $\beta_{\mathrm{T}}$, Wilson \& Schmida) of 0.5 between 3 and $6-\mathrm{cm}$ depths, at CIII. N/AMF recorded a $\beta_{\mathrm{T}=} 0.6$ in average among 6 and 9-cm depth at Cl; whereas for AMF treatment the highest value of $\beta_{\mathrm{T}}(0.4)$ was achieved from 3 and 6-cm depth, at CIII (Fig. 4c).

Cody index $\beta c_{O}$ from Control treatment was of 0.5 in average, from 3 and $6-\mathrm{cm}$ depth, at CIII. For treatment N/AMF the $\beta c_{O}$ value was 0.6 between 3 and 6-cm depth, at CIII; whereas for treatment AMF the $\beta c_{O}$ value was of 0.5 between 3 and 6-cm depth, at CIII (Fig. 4c; Table S7).

\section{Bacterivorous Amoebae Beta Diversity}

$B W$ value for bacterivorous amoebae from Control treatment, was 1.7, which was recorded at CIII, between 3 and 6-cm depths; whereas for N/AMF and AMF treatments the highest value of $\beta w$ was 1.4 and 1.3 from 3 and 6-cm and 6-9-cm depths, at CIII (Fig. 4d; Table S8).

Regarding specific depths gradient, bacterivorous beta diversity showed the following highest values: Control, $\beta_{C}=7$ between 6 and 9 -cm depth, at Cl; N/AMF, $\beta_{C}=16$ among 3 and 9-cm depths, at Cl; and AMF, $\beta_{C}=11$, between 6 and 9-cm depth, at CII (Fig. 4e; Table S8).

Page 5/14 
The $\beta_{T}$ index value for Control, N/AMF and AMF treatments were araund of 0.5 from the same 3 and 6 -cm depths, at CIII (Fig. $4 \mathrm{f}$ ). Moreover, $\beta_{C O}$ values for N/AMF treatment was of 0.6, while for AMF and Control treatments, this value was around of 0.5, at CIII (3 and 6-cm depth) (Fig. 4f; Table S8).

\section{AMF mycelium length and Pearson Correlation Coefficient with MPN and species richness of amoebae}

Form AMF microcosm, the longest AMF-mycelium length $(19 \mathrm{~cm})$ was achieved in $\mathrm{Cl}$ at 9-cm depth; however, for Cll showed the longest mycelium length $(9.5 \mathrm{~cm})$ was recorded at 6-cm depth, whereas for CIII, the longest mycelium length $(6.5 \mathrm{~cm})$ was registered at 6-cm depth. No AMF-mycelium was achieved from C (Non-planted) neither N/AMF microcosms (data not shown).

By considering data from AMF microcosm, the Cl showed a negative correlation between the NMP of amoebae with the AMF-mycelium ( $\rho=-0.9$; $81.7 \%$ determination), at 9 -cm depth. In contrast, the correlation of mycelium length with amoebae species richness was positive 0.4 (14\% determination). Species richness and length mycelium correlated $\rho=0.9$ (80\% determination) recorded in CIII (Fig. 5).

\section{Similarity Analysis}

Overall, Sørensen analysis revealed a core community composed mostly by bacterivorous; however; amoebae community composition changed when AMF was present (Fig. 6, B = red circles) when compared to $C$ and N/AMF microcosms (Fig. 6).

Amoebae species composition was dissimilar at microcosms which plants were established (N/AMF and AMF); furthermore, this dissimilarity was observed among their own compartments (Control microcosms) (Fig. 6). Species composition from the microcosms N/AMF showed a cluster (CIII-6 and CIII-9, with $98 \%$ of similarity); moreover, this cluster shared $68 \%$ of their species with the amoebae community registered at CII-9. There was observed N/AMF, $\mathrm{Cl}-3, \mathrm{Cl}-6$ and $\mathrm{Cl}-9$ were dissimilarity of their species communities; furthermore, the remaining communities from $\mathrm{Cll}$, shared less than $81 \%$ of species (Fig. 6).

For AMF microcosm, the compartments CII-3, CII-6 and CII-9 configured a cluster with $87 \%$ of similarity, Cll-6 and CII-9 shared $100 \%$ of their species this subgroup shared $63 \%$ their species with the communities from $\mathrm{Cl}$ and $\mathrm{CII}$ at AMF y N/AMF respectably. Subgroup conformed of CIII-3 and CIII-6 (77\%), but by adding the CIII-9 they shared $57 \%$ of species among these compartments (Fig. 6 ).

More specifically, bacterivorous communities from three depths shared species among all microcosms (AMF, N/AMF, and Control), if we considered those communities that shared at least $50 \%$ of their species, it is possible to found three different groups which are represented in the corresponding dendrogram (Fig S5a). Principal group was integrated by the communities from all treatments, but from this large group two 2 subgroups were detected. Other group was chained between communities founded from the AMF microcosms at the same compartment (CIII), regardless the sampling depth (Fig S5a). In contrast, communities registered for the Control microcosm had $62 \%$ similarity between CII and CIII, mainly at 3 and 6 -cm of depth (Fig S12a).

Protozoa-eater amoebae community was formed four groups: the first one involves the control from three compartments with $100 \%$ similarity. The third and large group were integrated by AMF and N/AMF microcosms with 62\% similarity (Fig S5b); moreover, AMF microcosms (Cl) at 3 and 6 -cm depth, showed $98 \%$ of similarity (Fig S5b).

\section{Discussion}

Amoebae vertical distribution of community was differentially affected by presence of either roots or AMF, and was dominated by bacterivorous amoebae.

Control presented the lowest species richness and abundance of amoebae individuals. However, species were heterogeneously distributed, being Amoebidae morphotype ( $\mathrm{VI})$ the most numerous. In this regard, bare soil is a heterogeneous environment in where microbial distribution depends on resources pockets which are heterogeneously distributed in soil matrix at microscale level. Moreover, moisture fluctuations and available food resources in edaphic microenvironments restrict both activity and reproductive capacity of protozoa [38]. These would explain the low similarity achieve for amoebae communities, which shared less than $30 \%$ of species among the compartments at unplanted microcosms (Control).

In contrast, N/AMF microcosms showed a significant increase of species richness, which was dominated by bacterivorous amoebae (morphotypes VIII and IV) around the root-soil (CI). Vahlkampfia and Hartmannella show preferences for certain bacterial species, and are capable of perceive, select, trace, or capture a great variety of preys [27]. In this case, roots without AMF increase amoeba species richness, thus, denoting an indirect "rhizosphere effect" on bacterivorous. Roots favor bacterial proliferation due to exudation of compounds that serve as carbon and energy sources [22]. This effect influence on the community of bacterial predators like nematodes and protozoa [28; 38], which may explain in part, the results obtained at N/AMF microcosms. 
AMF microcosms showed the higher species richness and amoebae individuals at Cll where only there was AMF-mycelium (hyphosphere) in comparison to $\mathrm{Cl}$ in which both roots and AMF-mycelium (mycorrhizosphere) were presented. Either mycorrhizosphere or hyphosphere contributes on exudation of organic compounds rich on carbon and energy that enhance bacterial communities $[9,10,12,43,44]$. In consequence, community and trophic groups of amoebae also increase around these hotspots, as observed in our experimental conditions, in which species richness in CII (mycorrhizosphere) was 54, and three predominant trophic groups were identified as bacterivorous, protozoa-eaters, and algae-eaters.

Overall, vertical amoebae distribution showed greatest species richness at 6-cm depth at the root zone (Cl) from N/AMF microcosms when compared to Control or AMF microcosms. The later reflects significant changes on amoebae communities at short distances of soil depths, especially in roots zones where there are available carbon sources for microbial activities [10,39]. These organic compounds may be used by predators as signal molecules to find preys; thus, diverse interactions between plants and microbial food web increase around these zones [40, 41].

In general, the lowest amoebae richness and quantity of individuals was found at CIII from all microcosms. For microcosms N/AMF and AMF, root growth was restricted for $\mathrm{Cll}$ and $\mathrm{CIII}$, but, the effect of AMF-mycelium significantly increase the species and individuals bacterivorous (CII). Furthermore, hyphosphere influence extended beyond the roots to reach both Cll and ClII, in which the average hyphal length was of $6.5 \mathrm{~cm}$, at 9 - $\mathrm{cm}$ depth.

Amoebae community around AMF-mycelium presented some species were exclusively found in this zone. Moreover, rare species were found in AMF microcosms (Table S4), and were different from those recorded at N/AMF and Control microcosms. In contrast, "common" species were very similar among the three microcosms (core community).

Amoebae are fourth element that plays part in soil-plant-mycorrhizal-microbiome interactions, and contributes on plant productivity by modelling the microbiome community, and by releasing nutrients [42]. This explains why the bacterivorous populations and protozoa-eater amoebae showed a significant increase in roots compartments (Cl), at both N/AMF and AMF microcosms.

Furthermore, AMF sustain a different microbial species set as revealed by the amoebae community recorded in our research. Bacterivorous species number was greater in presence of AMF-mycelium, but fungivorous amoebae was undetected. It is probably that bacterial set cohabiting the AMFmycelium may act as a "hidden scent" that helps on preventing activity of fungal predators [45], which may explain nonappearance of fungivorous amoebae at hyphosphere. Regardless trophic group, observed decrease on amoebae quantity at $\mathrm{Cl}$, had a negative correlation with presence of AMF in roots.

At trophic level, bacterivorous amoebae was dominant in all microcosms; however, their richness showed dissimilarities among microcosms. This indicates that all microcosms have similar functional activity of amoebae, but species identity changes among three microcosms.

Our results indicate that the greatest changes between communities $(B w)$ occurred at 3 and 6 -cm depth, in CIII of the three microcosms. The communities change rate $\left(B_{C}, B_{C O}\right.$ and $\left.B_{t}\right)$ corroborates modifications in amoebae communities from N/AMF rhizosphere soil which showed higher change rate, at CIII. These differentiations among species composition of amoebae communities in three microcosms; are related to a complex environmental gradients induced by either rhizosphere or mycorrhizosphere, when compared to unplanted soil. Furthermore, both functional zones support larger species richness and amoebae number.

\section{Conclusions}

At short term experimentation, presence of Rhizophagus intraradices influenced species distribution into trophic groups of amoebae around the Zea mays root zone, but more significantly due to the presence of AMF-mycelium in root-free compartments. Structure of amoebae community around AMF-mycelium was different, and some species were exclusively found in mycelium zone. Moreover, rare species found in AMF microcosms were different to those recorded from N/AMF and Control microcosms.

\section{Declarations}

\section{Acknowledgements}

First author acknowledges financial support from CONACyT-Mexico, during her postdoctoral position at Colegio de Postgraduados.

\section{Funding}

Not applicable.

\section{Competing Interests}

The authors declare no competing interests.

\section{Author Contributions}


Sandra Cortés-Pérez and Ronald Ferrera-Cerrato conceived and designed the experiments. Sandra Cortés-Pérez performed the laboratory experiments. Material preparation, data collection and analysis were performed by Sandra Cortés-Pérez. The first draft of the manuscript was written by Sandra Cortés-Pérez and all authors commented on previous versions of the manuscript. Alejandro Alarcón and Salvador Rodríguez-Zaragoza participated in critically reviewed the final manuscript, and all authors approved the final manuscript.

\section{Data Availability}

All data generated or analyzed during this study are included in this published article [and its supplementary information files as tables S1 and S3].

\section{Ethics declarations}

Not applicable.

\section{Ethics Approval}

Not applicable.

\section{Consent to Participate}

Not applicable.

\section{Consent for Publication}

Not applicable.

\section{Rights and permissions}

Not applicable.

\section{References}

1. Levin SA (2005) Self-organization and the emergence of complexity in ecological systems. Bioscience 55:1075-1079. https://doi.org/10.1641/0006-3568(2005)055[1075:SATEOC]2.0.C0;2

2. Bonkowski M, Jentschke G, Scheu S (2001) Contrasting effects of microbes in the rhizosphere: interactions of mycorrhiza (Paxillus involutus (Batsch) Fr.), naked amoebae (Protozoa) and Norway spruce seedling (Picea abies Karst.). Appl Soil Ecol 18: $193-204$. https://doi.org/10.1016/S0929-1393(01)00165-2

3. Finlay RD, Rosling A, Gadd GM (2006) Integrated nutrient cycles in forest ecosystems, the role of ectomycorrhizal fungi, Fungi in biogeochemical cycles, Cambridge, UK Cambridge University Press, pp. 28-50

4. Bonfante P, Anca IA (2009) Plants, Mycorrhizal Fungi, and Bacteria: A Network of Interactions. Annu Rev Microbiol 63:363-383. https://doi.org/10.1146/annurev.micro.091208.073504

5. Srnith SE, Smith EA (2012) Fresh perspectives on the roles of arbuscular mycorrhizal fungi in plant nutrition and growth. Mycologia 104:1, 1-13. https://doi.org/10.3852/11-229

6. Smith SE, Gianinazzi-Pearson V (1988) Physiological interactions between symbionts in vesicular-arbuscular mycorrhizal plants. Annu Rev Plant Physiol 39: 221-244. https://doi.org/10.1146/annurev.pp.39.060188.001253

7. Zhang L, Fan J, Ding X, He X, Zhang F, Feng G (2014) Hyphosphere interactions between an arbuscular mycorrhizal fungus and a phosphate solubilizing bacterium promote phytate mineralization in soil. Soil Biol Biochem 74: 177-183. https://doi.org/10.1016/j.soilbio.2014.03.004

8. Qin H, Brookes PC, Xu J (2016) Arbuscular mycorrhizal fungal hyphae alter soil bacterial community and enhance polychlorinated biphenyls dissipation. Front Microbiol 7:939. https://doi.org/10.3389/fmicb.2016.00939

9. Nuccio EE, Hodge A, Pett-Ridge J, Herman DJ, Weber PK, Firestone MK (2013) An arbuscular mycorrhizal fungus significantly modifies the soil bacterial community and nitrogen cycling during litter decomposition. Environ Microbiol 15:1870-1881. https://doi.org/10.1111/14622920.12081

10. Andrade G, Mihara KL, Linderman RG, Bethlenfalvay GJ (1997) Bacteria from rhizosphere and hyphosphere soils of different arbuscularmycorrhizal fungi. Plant and Soil. 192:71-79. https://doi.org/10.1023/A:1004249629643

11. Xavier LJC, Germida JJ (2003) Bacteria associated with Glomus clarum spores influence mycorrhizal activity. Soil Biol Biochem $35: 471-478$. https://doi.org/10.1016/S0038-0717(03)00003-8

12. Horii S, Ishii T (2006) Identification and function of Gigaspora margarita growth-promoting microorganisms. Symbiosis 41: $135-141$.

13. Horii S, Matsumura A, Cruz A, Ishii T (2008) Effect of arbuscular mycorrhizal fungi and their helper microorganisms on root colonization and growth of trifoliate orange seedlings. Proc Int Soc Citriculture 1: 567-571. 
14. Scheublin TR, Sanders IR, Keel C, van der Meer JR (2010) Characterisation of microbial communities colonizing the hyphal surfaces of arbuscular mycorrhizal fungi. ISME J 4: 752-763. https://doi.org/10.1038/ismej.2010.5

15. Frey-Klett P, Garbaye J, Tarkka M (2007) The mycorrhiza helper bacteria revisited. New Phytol 176:22-36. https://doi.org/10.1111/j.14698137.2007.02191.x

16. Battini F, Grønlund M, Agnolucci M, Giovannetti M, Jakobsen I (2017) Facilitation of phosphorus uptake in maize plants by mycorrhizosphere bacteria. Sci Rep 7:46-86. https://doi.org/10.1038/s41598-017-04959-0

17. Svenningsen NB, Watts-Williams SJ, Joner EJ, Battini F, Efthymiou A, Cruz-Paredes C, Nybroe O, Jakobsen I (2018) Suppression of the activity of arbuscular mycorrhizal fungi by the soil microbiota. ISME J 12:1296-1307. https://doi.org/10.1038/s41396-018-0059-3

18. Klein E, Ofek M, Katan J, Minz D, Gamliel A (2012) Soil suppressiveness to Fusarium disease: shifts in root microbiome associated with reduction of pathogen root colonization. Phytopathology 103:23-33. https://doi.org/10.1094/PHYTO-12-11-0349

19. Liu X, Zhang S, Jiang Q, Bai Y, Shen G, Li S, Ding W (2016) Using community analysis to explore bacterial indicators for disease suppression of tobacco bacterial wilt. Sci Rep 6:36773. https://doi.org/10.1038/srep36773

20. Christensen $\mathrm{H}$, Jakobsen I (1993) Reduction of bacterial growth by a vesicular-arbuscular mycorrhizal fungus in the rhizosphere of cucumber (Cucumis sativus L.). Biol Fertil Soils 15: 253-258. https://doi.org/10.1007/BF00337209

21. Azaizeh HA, Marschner A, Römheld V, Wittenmayer L (1995) Effects of a vesicular-arbuscular mycorrhizal fungus and other soil microorganisms on growth, mineral nutrient acquisition and root exudation of soil-grown maize plants. Mycorrhiza 5:321-327. https://doi.org/10.1007/BF00207404

22. Odelade KA, Babalola $O O$ (2019) Bacteria, fungi and archaea domains in rhizospheric soil and their effects in enhancing agricultural productivity. Int. J Environ Res Public Health 16: 3873. https://doi.org/10.3390/ijerph16203873

23. Leach JE, Triplett LR, Argueso CT, Trivedi P (2017) Communication in the Phytobiome. ISSUE 169: (4) 587-596. https://doi.org/10.1016/j.cell.2017.04.025

24. Baltar F, Palovaara J, Unrein F, Catala P, Horňák K, Šimek K, Vaqué D, Massana R, Gasol JM, Pinhassi J (2016) Marine bacterial community structure resilience to changes in protist predation under phytoplankton bloom conditions. ISME J 10(3): 568-581. https://doi.org/10.1038/ismej.2015.135

25. Wootton EC, Zubkov MV, Jones DH, Jones RH, Martel CM, Thornton CA, Roberts EC (2007) Biochemical prey recognition by planktonic protozoa. Environ Microbiol. 9(1):216-22. https://doi.org/10.1111/j.1462-2920.2006.01130.x

26. Clarholm M (2002) Bacteria and protozoa as integral components of the forest ecosystem - Their role in creating a naturally varied soil fertility. Antonie van Leeuwenhoek. https://doi.org/10.1023/a:1020543424098

27. Darbyshire JF (1994) Soil Protozoa. CABI Publishing Series. Colaborador C.A.B. International. Michigan University. 209 pp.

28. Griffiths BS (1994) Microbial-feeding nematodes and protozoa in soil: Their effects on microbial activity and nitrogen mineralization in decomposition hotspots and the rhizosphere. Plant Soil 164: 25-33. https://doi.org/10.1007/BF00010107

29. Bonkowski M, Clarholm M (2012) Stimulation of Plant Growth through Interactions of Bacteria and Protozoa: Testing the Auxiliary Microbial Loop Hypothesis. Acta Protozool 51(3). https://doi.org/10.4467/16890027AP.12.019.0765

30. Singh BN (1975) Aerobic small free-living amoebae. In: Pathogenic and non-pathogenic Amoebae. The Macmillan PressLTD, pp 1-32

31. Phillips JM, Hayman DS (1970) Improved procedures for clearing and staining parasitic and vesicular arbuscular mycorrhizal fungi for rapid assessment of infection. Br Mycol Soc 55(1): 158-IN18. https://doi.org/10.1016/S0007-1536(70)80110-3

32. Tennant $D$ (1975) A test of a modified line intersect method of estimating root length. J of Ecol 63: 995-1001. https://doi.org/10.2307/2258617

33. McCune B, Mefford MJ (2016) PC-ORD. Multivariate Analysis of Ecological Data. Version 7. MjM Software Design, Gleneden Beach, Oregon, U.S.A.

34. Shannon CE, Weaver W (1949) The mathematical theory of communication.University Illinois Press, Urbana

35. Simpson EH (1949) Measurement of diversity. Nature 163:688. doi:10.1038/163688a0

36. Greenwood PE (1996) A guide to chi-squared testing. JohnWiley \& Sons, New York

37. Koleff P, Gaston KJ, Lennon JJ (2003) Measuring beta diversity for presence-absence data. J Anim Ecol 72: $367-382$. https://doi.org/10.1046/j.1365-2656.2003.00710.x

38. Rodriguez-Zaragoza S, Mayzlish E, Steinberger Y (2005) Vertical Distribution of the Free-Living Amoeba Population in Soil under Desert Shrubs in the Negev Desert, Israel. Appl Environ Microbiol 71(4): 2053-2060 https://doi.org/10.1128/AEM.71.4.2053-2060.2005

39. Mathesius U, Weinman JJ, Rolfe BG, Djordjevic MA (2000) Rhizobia can induce nodules in white clover by 'hijacking' mature cortical cells activated during lateral root development. Mol Plant Microbe Interact 13: 170-182. https://doi.org/10.1094/MPMI.2000.13.2.170

40. Lareen A, Burton F, Schäfer P (2016) Plant root-microbe communication in shaping root microbiomes. Plant Mol Biol 90(6):575-587. https://doi.org/10.1007/s11103-015-0417-8

41. Philippot L, Raaijmakers J, Lemanceau P, Wim H (2013) Going back to the roots: the microbial ecology of the rhizosphere. Nat Rev Microbiol 11: 789-799. https://doi.org/10.1038/nrmicro3109

Page $9 / 14$ 
42. Gao C, Montoya L, Xu L, Madera M, Hollingsworth J, Purdom E, Hutmacher RB, Dahlberg JA, Coleman-Derr D, Lemaux PG, Taylor JW (2019) Strong succession in arbuscular mycorrhizal fungal communities. ISME J 13: 214-226. https://doi.org/10.1038/s41396-018-0264-0

43. Filion M, St-Arnaud M, Fortin JA (1999) Direct interaction between the arbuscular mycorrhizal fungus Glomus intraradices and different rhizosphere microorganisms. New Phytologist 141(3): 525-33. https://doi.org/10.1046/j.1469-8137.1999.00366.x

44. Marschner GE, H, Jakobsen I (1995) Role of arbuscular mycorrhizal fungi in uptake of phosphorus and nitrogen from soil. Crit Rev Biotechnol 15: 257-270. https://doi.org/10.3109/07388559509147412

45. Brussaard L, Kuyper TW, de Goede RG. (2001). On the relationships between nematodes, mycorrhizal fungi and plants: functional composition of species and plant performance. Plant and Soil 232, 155-165. https://doi.org/10.1023/A:1010398322637

\section{Figures}

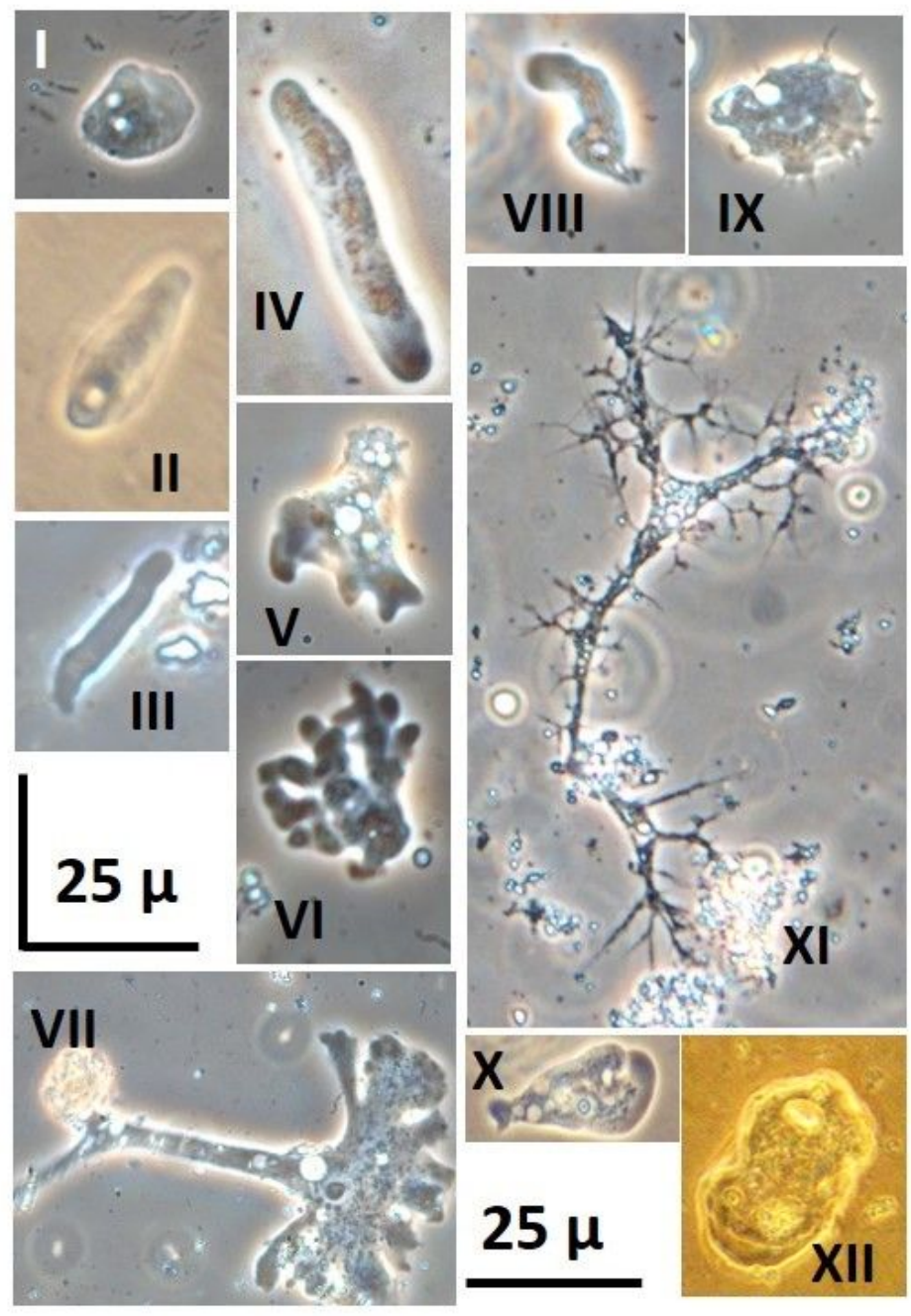

Figure 1

Amoebae categorization into 12 different morphotypes as follows: The first 4 types corresponded to limax form, no subpseudopodia. T I corresponded to fan-shaped-like amoebae, type species Vannella platypodia. T II to lanceolate morphotype-like, type species Platyamoeba placida. T III corresponded to worm-like amoebae, type species Vermamoeba (Hartmannella) vermiformis. T IV corresponded to monotactic morphotype, type species Saccamoeba stagnicola. T V corresponded to fan-shape amoebae with conical and/or mamiliform pseudopods, type species Mayorella cultura. T VI corresponded to polypoidal amoebae, type species Polycaos sp. T VII corresponded to web-like amoeba, type species Leptomyxa sp. T VIII corresponded to the limax amoebae with eruptive pseudopodia, type species Vahlkampfia enterica. T IX corresponded to Acanthamoeba sp-like amoebae. T X Amoebae showing a triangular form when fast-moving, with eruptive pseudopod, type species Tetramitus sp; T XI resembling a "root structure", type species Biomyxa sp. and T XII amoebae includes the oval and wrinkled shape, type species Thecamoeba terricola 


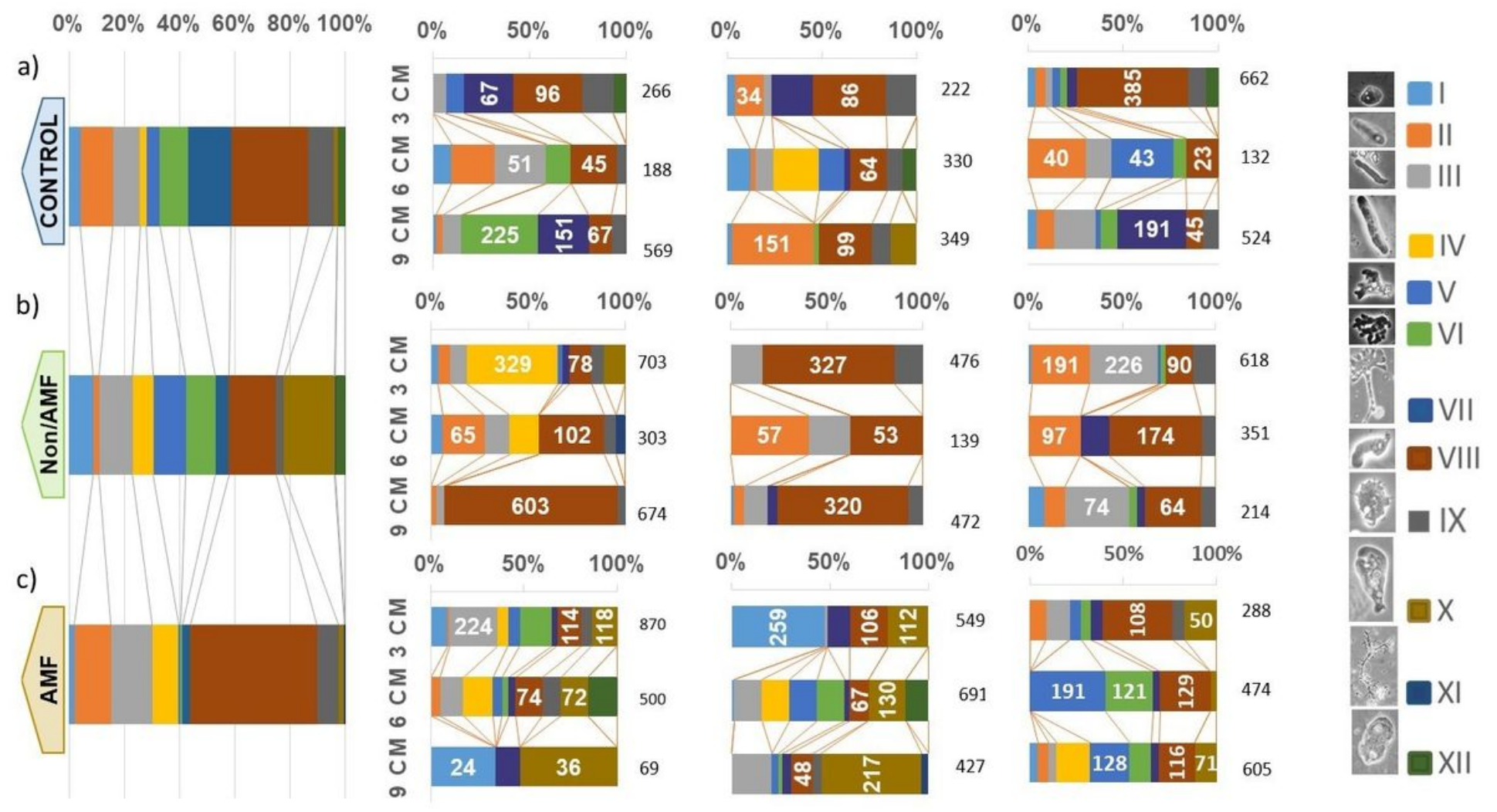

Figure 2

Relative abundance of 12 amoebae morphotypes from treatments and control group. Colors in banding pattern are the graphical representation of each morphotype relative abundance in control and treatments (3a control, 3b Non/AMF and 3c AMF), as well as by depths (3, 6 and 9-cm depth) and compartment of microcosms ( $\mathrm{Cl}, \mathrm{CIl}$, and CIII).The 12 morphotypes are listed according to Fig. 2 as. TI: Vannella platypodia, fan-shaped-like amoebae. T II; Platyamoeba placida. T III; Vermamoeba. T IV; Saccamoeba stagnicola. None of the type I to type IV amoebae showed subpseudopodia (limax form); V; Mayorella cultura. T VI; polypoidal amoebae. T VII; Leptomyxa sp-like. T VIII; Vahlkampfia enterica-like. T IX; Acanthamoeba sp. T X; Tetramitus sp. T XI resembling a "root structure", Biomyxa-like and T XIl; Thecamoeba terricola-like
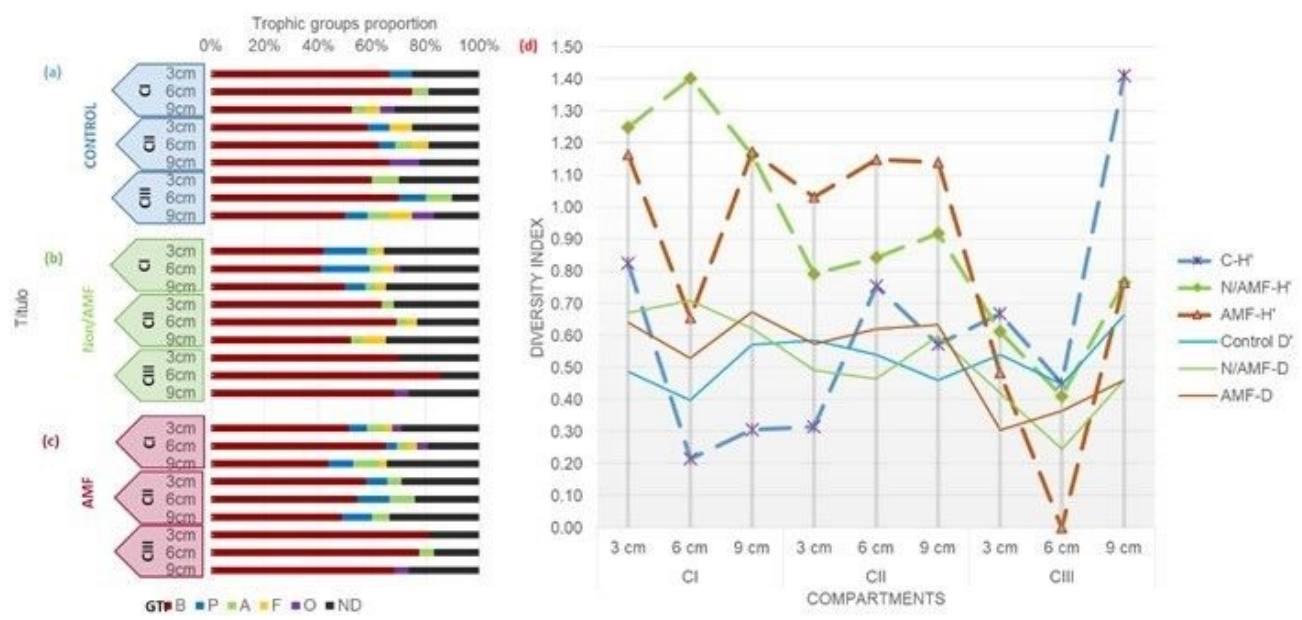

\section{Figure 3}

Relative importance of trophic groups (A). Abbreviations: N/AMF: treatment without mycorrhizal fungi. AMF: treatment with mycorrhizal fungi. Control (blue), N/AMF (Green) and AMF (Purple). The banding patterns are the graphical representation of the relative importance of each trophic group inside every depth $(3,6$ and 9-cm) of each compartment $(\mathrm{Cl}, \mathrm{CII}$, and $\mathrm{CIII})$ of microcosms. The five trophic groups were present at 3-cm in the planted compartment $(\mathrm{Cl})$ of N/AMF and AMF treatments and in the $6 \mathrm{~cm}$ depth of the N/AMF plants. Abbreviations: A, algivorous-amoebae; $B$, bacterivorous amoebae; F, fungivorous amoebae; $\mathrm{O}$ omnivorous amoebae; $\mathrm{P}$, protozoa-eater amoebae and no feeding preferences determined or reported in the literature (ND). B) Trophic diversity index Shannon-Weaver (H') and Simpson (D) from control (Blue rows), N/AMF (green) and AMF (purple) 

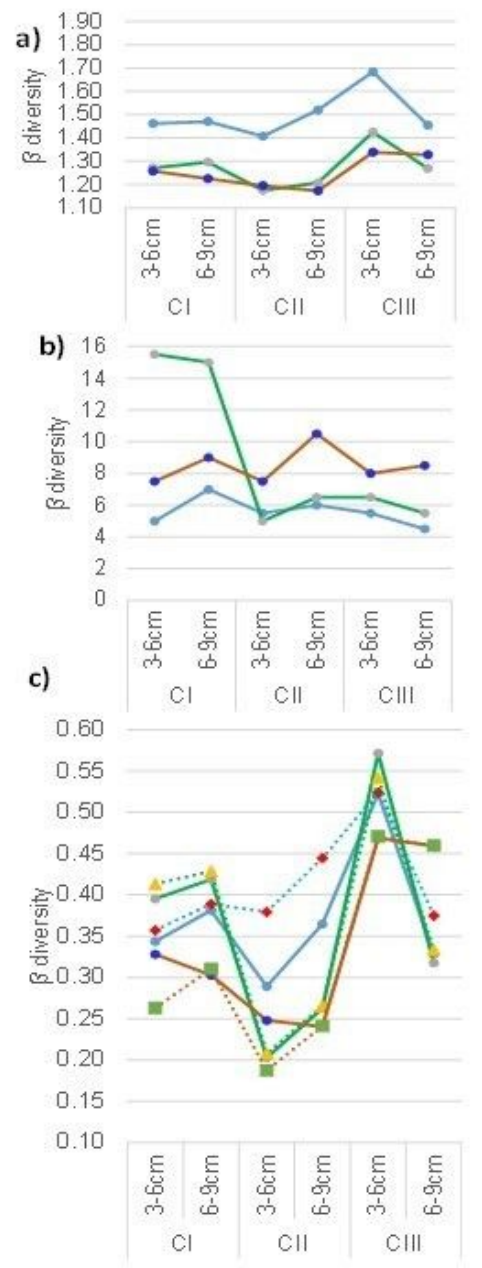

e)
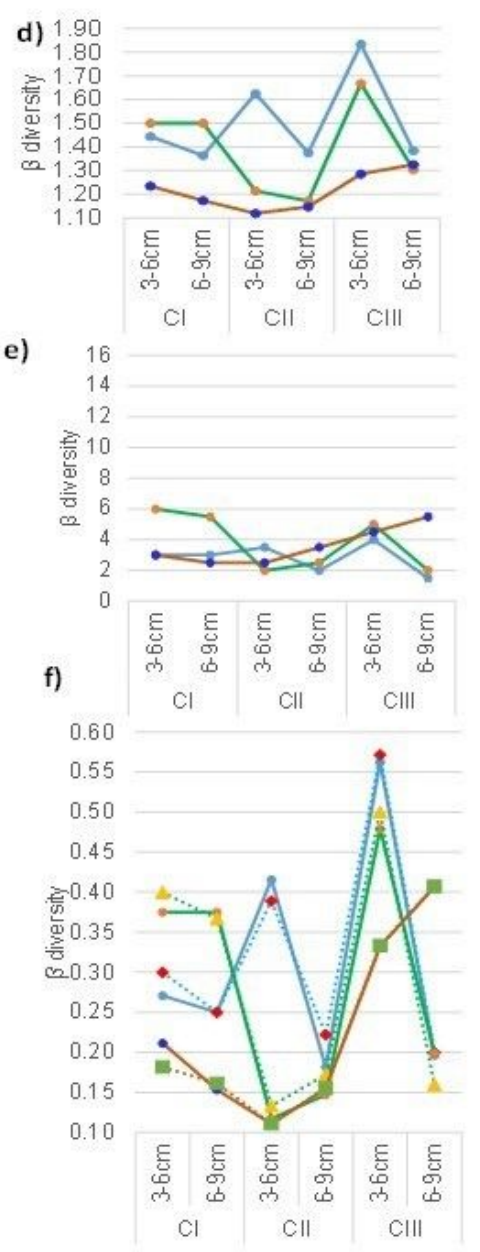

$\because$ Control $\beta \mathrm{co} \quad \ldots \leftrightarrow$ Control $\beta T$

-Non/AMF $\beta$ Co .... Non/AMF $\beta T$

$\because \mathrm{AMF} \beta \mathrm{CO} \quad$..

\section{Figure 4}

$\beta$-diversity values plotted against depths in $\mathrm{cm}$ to $\mathrm{A}-\mathrm{C}$ show the values of communities from treatments calculated with presence-absence data. While the d-f graphs show $\beta$-diversity values of bacterivorous species from 3 - 6-cm depth and 6 - 9-cm depth from each compartment (Cl, Cll and CIII). Abbreviations: $\mathrm{C}$ = control group, blue line; N/AMF = treatment without mycorrhizal, green line; AMF; treatment with mycorrhizal, brown line. Graphics: A) Whittaker index or $\beta W$ (1992) ( $0 \geq 2$ = number of communities used for calculation). B) Cody index or $\beta C$ (1975). C) BCO = Cody index (1993) and Wilson \& Shmida or $\beta T$ (1984). D) $\beta$ W calculation for bacterivorous guild $(0 \geq 2)$. E) Cody index or $\beta C$ (1975) by bacterivorous guild. F) BCO and $\beta T$ (1984) bacterivorous guild 


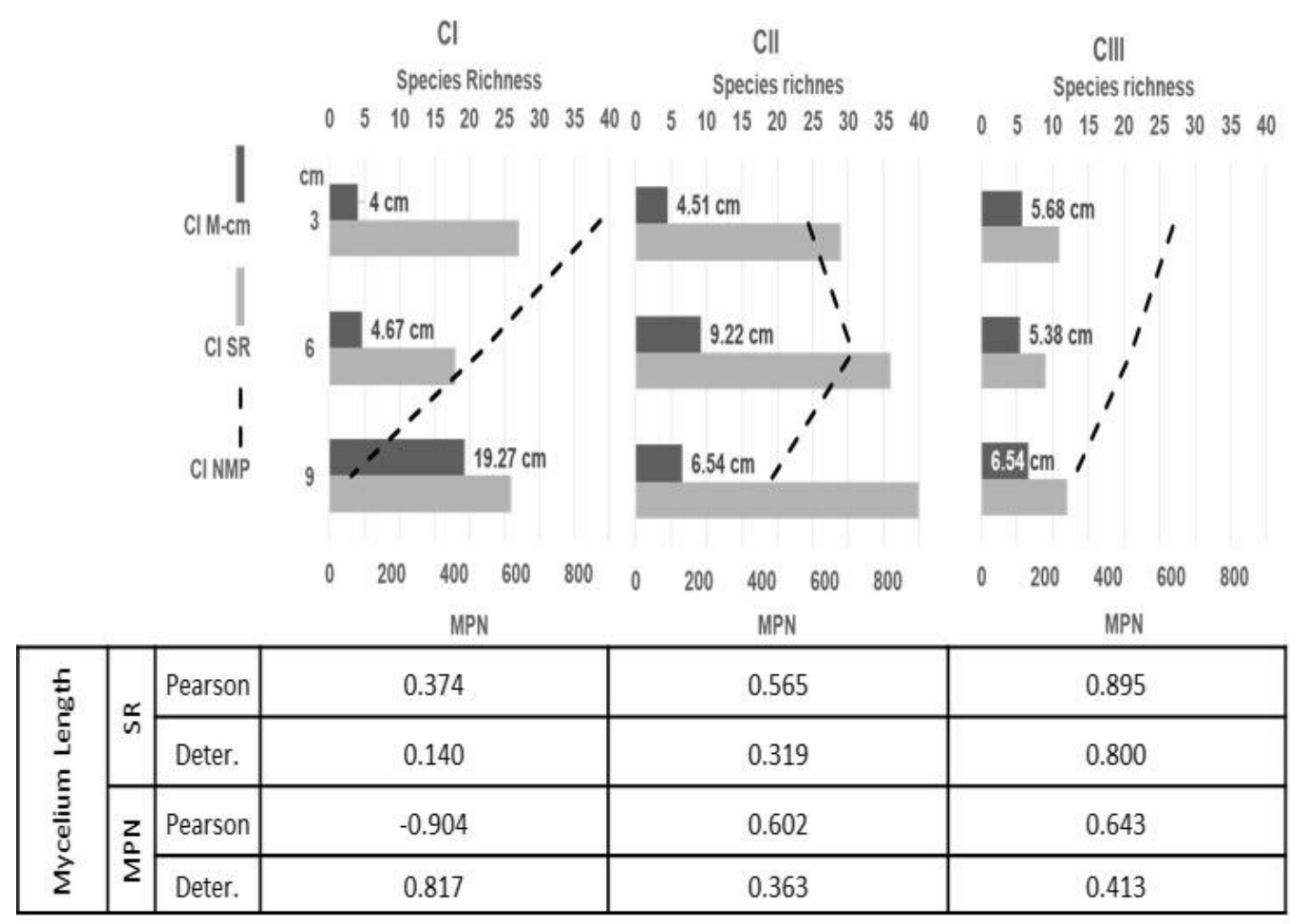

Figure 5

Mycelium length in cm (M-cm = black bar); Species richness (SR = black gray); MPN; Most probable number (broken line); AMF microcosms Pearson's correlation index between mycelium surface area, species richness and MPN. Abbreviations: $\mathrm{Cl}, \mathrm{Cll}$ and $\mathrm{CIII}$ are the corresponding compartments of microcosms
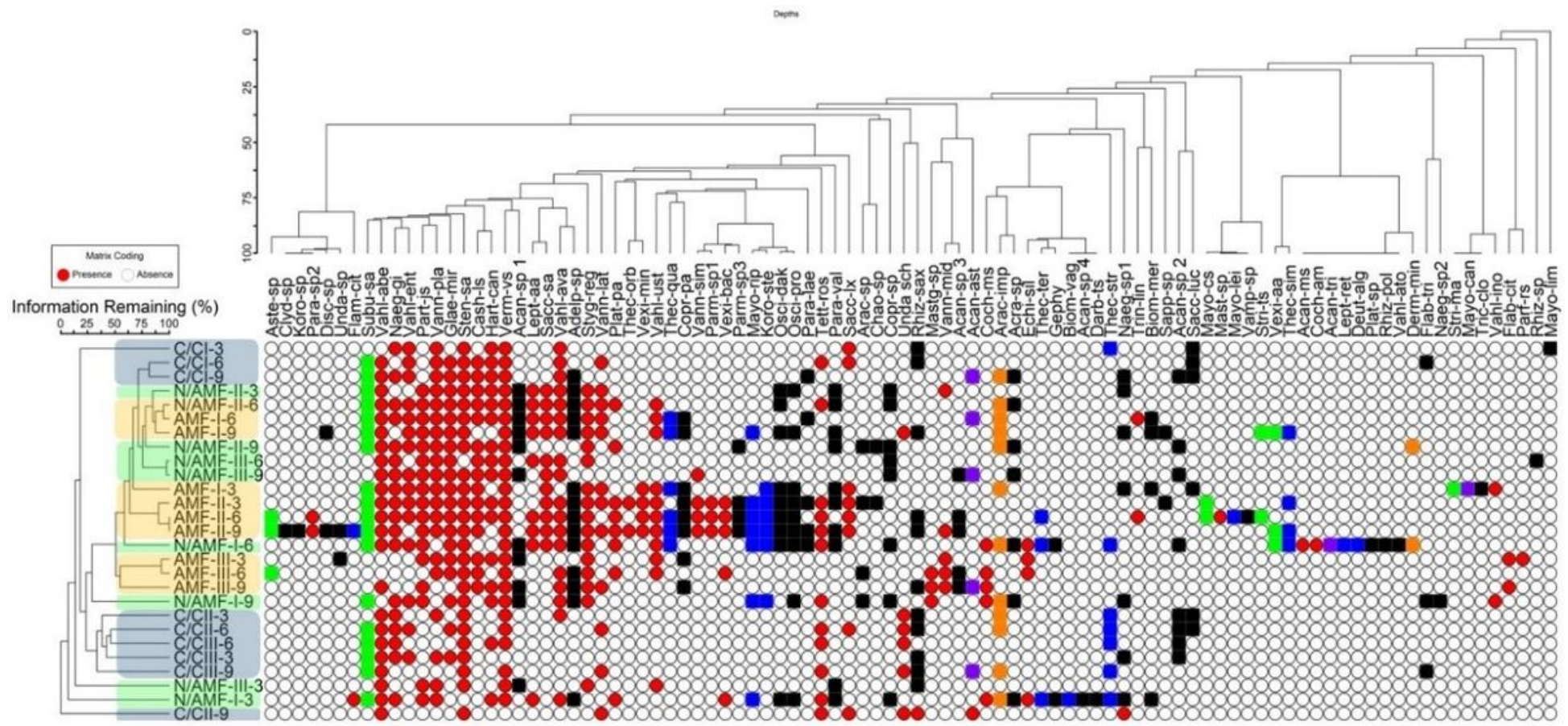

Figure 6

Sørensen analysis of amoebae communities from treatments at different compartments and depths. Cluster analysis of amoebae communities showed the similarity between communities is due to the bacterivorous and algivorous groups in the first instance and by protozoa eater group in the second place. Captions at the dendrograms left side are compartments abbreviations for control and treatments as follows: C, unplanted-sandy-soil; N/AMF; planted-sandy-soil; AMF, mycorrhizal-plant. Latin number from the compartment of mycorrhizospheric-box and the Arabic number denoting 
the depth of sample (3, 6 and 9). Color code is as follows: Green box = N/AMF treatment; Brown box = AMF treatment. Red circles: bacterivorous species. Blue circles: Protozoa-eater amoebae species. Green circles: algae-eaters species. Purple circles: omnivorous. Orange circles: fungivorous

\section{Supplementary Files}

This is a list of supplementary files associated with this preprint. Click to download.

- FiguresSupplementalMaterialCortesPerezetal..docx

- TablesSupplementalMaterialCortesPerezetal2021.docx 